\title{
RANCANGAN D-OPTIMAL UNTUK MODEL EKSPONENSIAL GENERAL
}

\author{
Tatik Widiharih ${ }^{1}$, Sri Haryatmi ${ }^{2}$, Gunardi ${ }^{3}$ \\ ${ }^{1}$ Dosen Jurusan Statistika FSM UNDIP, widiharih@gmail.com \\ ${ }^{2}$ Dosen Jurusan Matematika UGM, s_kartiko@yahoo.com \\ ${ }^{3}$ Dosen Jurusan Matematika UGM, gunardi@ugm.ac.id
}

\begin{abstract}
Exponential model is widely used in biology, chemistry, pharmacokinetics and microbiology. Doptimal criteria is criteria with the purpuse to minimize the variance of the estimator of parameters in the model. In this paper will discuss the D-optimal design for the generalized exponential model with homoscedastics errore assumtion. We used minimally supported design with the proportion of each design point is uniform. The optimization is used modified Newton, and the results obtained that the design points are interior points of the design region.
\end{abstract}

Keywords: D-Optimal, Generalized Exponential, Minimally Supported Design, Support Point, Homoscedastics

\section{Pendahuluan}

Sebelum melakukan pengamatan terhadap penelitian diperlukan rancangan yang sesuai untuk menegaskan tujuan atau kriteria yang diinginkan. Masalah utama dalam perancangan percobaan adalah bagaimana menentukan titik-titik rancangan yang akan dicobakan beserta ulangannya sehingga memenuhi criteria yang telah ditetapkan. Penentuan titik-titik rancangan bisa dilakukan bila peneliti telah menetapkan pola hubungan antara variabel faktor dan variabel respon, serta kriteria keoptimalan yang diinginkan.

Kriteria rancangan D-optimal merupakan kriteria dengan tujuan meminimalkan variansi dari penduga parameter dalam model. Pada awalnya kriteria $D$-optimal digunakan untuk model regresi linear. Pada kasus error bersifat homoskedastik telah diteliti diantaranya oleh Atkinson et al. ${ }^{[1]}$, Fang ${ }^{[7]}$, Imhof et al. ${ }^{[10]}$. Sedangkan untuk kasus error bersifat heteroskedastik, dengan beberapa kasus fungsi bobot juga telah diteliti, diantaranya Antille et al. ${ }^{[2]}$, Fang ${ }^{[6]}$, Dette and Trampisch ${ }^{[4]}$ dan Widiharih dkk. ${ }^{[13]}$ menggunakan tiga macam fungsi bobot dan diaplikasikan pada regresi polynomial derajad tiga. Dari penelitian yang telah dilakukan tersebut baik untuk kasus homokedastik maupun heteroskedastik kriteria $D$-optimal dipenuhi bila banyaknya titik rancangan yang dicobakan sama dengan banyaknya parameter dalam model dengan ulangan (proporsi/bobot) setiap titik rancangan sama. Model nonlinear dengan bentuk umum:

$$
y=\eta(x, \beta)+\varepsilon
$$

Penentukan kriteria D-optimal dilakukan dengan cara Persamaan (1) dilinearkan terlebih dahulu. Salah satu cara yang digunakan adalah ekspansi deret Taylor sampai dengan derajat satu. Hal ini dapat dilihat diantaranya pada Atkinson et al. ${ }^{[1]}$ dan Schwabe ${ }^{[12]}$.

Model regresi nonlinear yang banyak digunakan diantaranya model regresi eksponensial. Regresi eksponensial ini dapat diaplikasikan pada bidang biologi, kimia, pharmacokinetic dan mikrobiologi. Han and Chaloner ${ }^{[9]}$ menggunakan model: $y=\alpha+\beta e^{-\lambda x}+\varepsilon, \quad x \geq 0, \alpha, \beta>0$, yang diaplikasikan pada bidang pharmacokinetic. Sedangkan Dette et al. ${ }^{[3]}$ menggunakan model yang merupakan jumlahan dari bentuk 
eksponensial: $y=\sum_{i=1}^{k} \alpha_{i} e^{-\beta_{i} x}+\varepsilon, \quad x \geq 0, \alpha_{i}, \beta_{i}>0$, yang diaplikasikan pada bidang biologi. Dette and Pepelyshev [5] menggunakan model sigmoidal untuk empat macam model yaitu: model regresi eksponensial dengan bentuk $y=\alpha-\beta e^{-\lambda x}+\varepsilon$, model regresi Weibull dengan bentuk $y=\alpha-\beta e^{-\lambda x^{\gamma}} \varepsilon$, model regresi logistic dengan bentuk: $y=\frac{\alpha}{\alpha+\beta e^{-\lambda x}}+\varepsilon$, dan model regresi Richards dengan bentuk $y=\frac{\alpha}{\left(\alpha+\beta e^{-\lambda x}\right)^{\gamma}}+\varepsilon$. $\mathrm{Li}^{[8]}$ menggunakan model regresi Gompertz dengan bentuk : $y=\beta$. exp $\left(-e^{-\gamma(x-\tau)}\right)$ yang diaplikasikan pada bidang biologi.

Model eksponensial tergeneral dapat diaplikasikan pada kurva pertumbuhan khususnya untuk kasus respon dengan pola naik mencapai maksimum kemudian turun kembali dan pada titik tertentu relatif konstan mendekati nol. Model ini digunakan untuk menggambarkan pola pertumbuhan gulma. Respon yang diamati adalah banyaknya gulma yang mati setelah mendapat perlakuan tertentu (penyemprotan dengan obat dan dosis tertentu).

Pada makalah ini akan dibahas rancangan D-optimal untuk model eksponensial tergeneral berikut :

$$
y=\alpha \beta e^{-\alpha x}\left(1-e^{-\alpha x}\right)^{\beta-1}+\varepsilon, x>0, \alpha>0, \beta \geq 1
$$

dengan $\varepsilon$ merupakan variabel acak dengan rata-rata nol dan variansi konstan $\sigma^{2}$. Grafik dari model (2) sangat spesifik dengan unimodal di titik $x=\frac{\ln (\beta)}{\alpha}$.

\section{Rancangan D-optimal Untuk Model Non Linear}

Model nonlinear yang digunakan di sini seperti pada Persamaan (1) yaitu: $y=\eta(x, \beta)+\varepsilon$. Rancangan dengan $\mathrm{p}$ buah titik rancangan dinotasikan dengan:

dengan: $w_{i}=\frac{r_{i}}{n}$

$$
\xi=\left(\begin{array}{cccc}
x_{1} & x_{2} & \cdots & x_{p} \\
w_{1} & w_{2} & \cdots & w_{p}
\end{array}\right)
$$

$r_{i}$ : banyaknya ulangan untuk titik rancangan $x_{i}$

$n$ : banyaknya pengamatan dan $n=\sum_{i=1}^{p} r_{i}$

$\sum_{i=1}^{p} w_{i}=1$

Matriks informasi dari rancangan (3) adalah:

$$
\boldsymbol{M}(\xi)=\sum_{i=1}^{d} w_{i} \boldsymbol{h}(\boldsymbol{x}) \boldsymbol{h}^{\boldsymbol{T}}(\boldsymbol{x})
$$

merupakan matriks simetri berukuran $k x k$ dengan $k$ adalah banyaknya parameter dalam model, dengan: $\boldsymbol{h}(\boldsymbol{x})=\left(\frac{\partial \boldsymbol{\eta}(\boldsymbol{x}, \boldsymbol{\beta})}{\partial \beta_{1}}, \frac{\partial \boldsymbol{\eta}(\boldsymbol{x}, \boldsymbol{\beta})}{\partial \beta_{2}}, \ldots, \frac{\partial \boldsymbol{\eta}(\boldsymbol{x}, \boldsymbol{\beta})}{\partial \beta_{k}}\right)^{T}$. Fungsi dispersi (variansi terstandar) yang bersesuaian dengan rancangan $\xi$ adalah:

$$
\mathrm{d}(x, \xi)=\boldsymbol{h}^{\boldsymbol{T}}(\boldsymbol{x}) \mathbf{M}^{-1}(\xi) \mathbf{h}(\boldsymbol{x})
$$

Nilai dari variansi terstandar untuk rancangan D-optimal antara nol sampai dengan $k$ ( $k$ : banyaknya parameter dalam model) dan maksimum dari variansi terstandar terjadi pada titik-titik rancangan. Berikut definisi dari rancangan dengan kriteria D-optimal.

Definisi 1. Atkinson et al. ${ }^{[1]}$

Kriteria D-optimal adalah kriteria yang diperoleh dengan cara meminimumkan $\Psi\{\boldsymbol{M}(\xi)\}$ dengan: $\Psi\{\boldsymbol{M}(\xi)\}=\log \left|\boldsymbol{M}^{-\mathbf{1}}(\xi)\right|=-\log |\boldsymbol{M}(\xi)|$ 
Berdasarkan Definisi 1, kriteria D-optimal diperoleh dengan cara memaksimalkan | $(\boldsymbol{M}(\xi)) \mid$. Untuk menunjukan bahwa rancangan $\boldsymbol{\xi}$ seperti pada Persamaan (3) memenuhi kriteria D-optimal digunakan Teorema Equivalensi Tergeneral dari Kiefer and Wolfowitz ${ }^{[11]}$ berikut:

Teorema 1, Teorema Equivalensi Tergeneral,

Tiga kondisi berikut adalah equivalen:

1. Rancangan $\xi^{*}$ memaksimalkan $|M(\xi)|$

2. Rancangan $\xi^{*}$ meminimumkan $\max _{x} d(x, \xi)$

3. $\max _{x} d(x, \xi)=k$, dengan $k$ adalah banyaknya parameter dalam model.

Secara ringkas Teorema Equivalensi Tergeneral dapat dinyakan sebagai berikut:

Rancangan $\boldsymbol{\xi}^{*}$ memaksimalkan $|M(\xi)| \Leftrightarrow \mathrm{d}(x, \xi)=\boldsymbol{h}^{\boldsymbol{T}}(\boldsymbol{x}) \boldsymbol{M}^{-\mathbf{1}}(\boldsymbol{\xi}) \boldsymbol{h}(\boldsymbol{x}) \leq \mathrm{k}$

Untuk menunjukkan bahwa rancangan $\xi$ seperti pada Persamaan (3) merupakan rancangan D-optimal dengan melakukan cheking bahwa terpenuhinya:

$$
\mathrm{d}(x, \xi)=\boldsymbol{h}^{\boldsymbol{T}}(\boldsymbol{x}) \boldsymbol{M}^{-1}(\xi) \boldsymbol{h}(\boldsymbol{x}) \leq \mathrm{k}
$$

\section{Rancangan D-optimal Untuk Model Eksponensial Tergeneral.}

Model eksponensial tergeneral seperti pada Persamaan (2) sebagai berikut:

$$
y=\alpha \beta e^{-\alpha x}\left(1-e^{-\alpha x}\right)^{\beta-1}+\varepsilon, x>0, \alpha>0, \beta \geq 1 \text {. }
$$

Grafik dari model eksponensial tergeneral untuk beberapa nilai $\alpha$ dengan $\beta=1.5$ seperti pada Gambar 1 berikut:

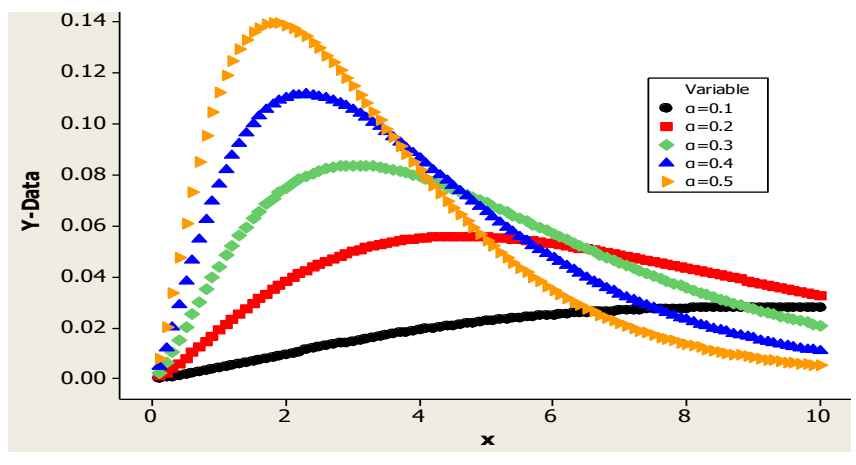

Gambar 1. Model Eksponensial Tergeneral untuk Beberapa Nilai $\alpha$ dengan $\beta=1.5$

Untuk menentukan rancangan D-optimal (menentukan titik-titik rancangan dan proporsinya sehingga terpenuhi kriteria D-optimal) dari model seperti Persamaan (2) dengan menggunakan Lemma berikut:

\section{Lemma 1.}

Titik-titik rancangan D-optimal untuk model eksponensial tergeneral (2) adalah $x_{1}$ dan $x_{2}$ dengan proporsi sama yaitu $0.5, x_{1}$ dan $x_{2}$ diperoleh dengan memaksimumkan :

$$
\begin{aligned}
|M(\xi)| & \propto \alpha^{2} \beta^{2} e^{-2 \alpha\left(x_{1}+x_{2}\right)}\left(1-e^{-\alpha x_{1}}\right)^{2 \beta-4}\left(1-e^{-\alpha x_{2}}\right)^{2 \beta-4}(A-B)^{2} \\
\text { dengan: } A & =\left(1-e^{-\alpha x_{2}}\right)\left(1+\beta \ln \left(1-e^{-\alpha x_{2}}\right)\right)\left(\left(1-e^{-\alpha x_{1}}\right)+\alpha x_{1}\left(\beta e^{-\alpha x_{1}}-1\right)\right) \\
B & =\left(1-e^{-\alpha x_{1}}\right)\left(1+\beta \ln \left(1-e^{-\alpha x_{1}}\right)\right)\left(\left(1-e^{-\alpha x_{2}}\right)+\alpha x_{2}\left(\beta e^{-\alpha x_{2}}-1\right)\right)
\end{aligned}
$$


Bukti:

$$
\boldsymbol{h}(\boldsymbol{x})=\left(\frac{\partial \eta(x, \alpha, \beta)}{\partial \alpha}, \frac{\partial \eta(x, \alpha, \beta)}{\partial \beta}\right)^{T}
$$

dengan: $\eta(x, \alpha, \beta)=\alpha \beta e^{-\alpha x}\left(1-e^{-\alpha x}\right)^{\beta-1}$.

$\left.A_{1}=\frac{\partial \eta(x, \alpha, \beta)}{\partial \alpha}=\beta e^{-\alpha x}\left(1-e^{-\alpha x}\right)^{\beta-2}\left[\left(1-e^{-\alpha x}\right)(1-\alpha x)+\alpha x(\beta-1) e^{-\alpha x}\right)\right]$

$A_{2}=\frac{\partial \eta(x, \alpha, \beta)}{\partial \beta}=\alpha e^{-\alpha x}\left(1-e^{-\alpha x}\right)^{\beta-1}\left[1+\beta \ln \left(1-e^{-\alpha x}\right)\right]$

$\boldsymbol{h}(\boldsymbol{x})=\left(A_{1}, A_{2}\right)^{T}$, karena digunakan rancangan minimal sehingga:

$$
\xi=\left(\begin{array}{cc}
x_{1} & x_{2} \\
0.5 & 0.5
\end{array}\right)
$$

Matriks informasi yang sesuai dengan rancangan $\xi$ pada Persamaan (8) adalah:

dengan :

$$
\boldsymbol{M}(\xi)=\left(\begin{array}{ll}
m_{11} & m_{12} \\
m_{12} & m_{22}
\end{array}\right)
$$

$\left.m_{11}=\sum_{i=1}^{2} 0.5 \beta^{2} e^{-2 \alpha x_{i}}\left(1-e^{-\alpha x_{i}}\right)^{2(\beta-2)}\left[\left(1-e^{-\alpha x_{i}}\right)\left(1-\alpha x_{i}\right)+\alpha x_{i}(\beta-1) e^{-\alpha x_{i}}\right)\right]^{2}$

$m_{12}=\sum_{i=1}^{2} 0.5 \alpha \beta e^{-2 \alpha x_{i}}\left(1-e^{-\alpha x_{i}}\right)^{2 \beta-3}\left[\left(1-e^{-\alpha x_{i}}\right)\left(1-\alpha x_{i}\right)+\alpha x_{i}(\beta-\right.$

1) $\left.\left.e^{-\alpha x_{i}}\right)\right]\left[1+\beta \ln \left(1-e^{-\alpha x_{i}}\right)\right]$

$m_{12}=\sum_{i=1}^{2} 0.5 \alpha^{2} e^{-2 \alpha x_{i}}\left(1-e^{-\alpha x_{i}}\right)^{2(\beta-1)}\left[1+\beta \ln \left(1-e^{-\alpha x_{i}}\right)\right]^{2}$

Determinan dari $\boldsymbol{M}(\xi)$ adalah : $|\boldsymbol{M}(\xi)|=m_{11} m_{22}-m_{12}^{2}$ diperoleh:

$|M(\xi)| \propto \alpha^{2} \beta^{2} e^{-2 \alpha\left(x_{1}+x_{2}\right)}\left(1-e^{-\alpha x_{1}}\right)^{2 \beta-4}\left(1-e^{-\alpha x_{2}}\right)^{2 \beta-4}(A-B)^{2}$,

seperti pada Persamaan (7). $x_{1}$ dan $x_{2}$ dipilih sehingga $|\boldsymbol{M}(\xi)|$ maksimum.

Perhitungan secara numeris titik-titik rancangan D-optimal model (2) untuk beberapa harga $\alpha$ dan $\beta$ dengan menggunakan metode modifikasi Newton (Modified Newton) seperti pada Tabel 1 berikut:

Tabel 1. Titik Rancangan D-optimal Model (2) Untuk Beberapa Harga $\alpha$ dan $\beta$

\begin{tabular}{cccc}
\hline$\alpha$ & $\beta$ & $x_{1}$ & $x_{2}$ \\
\hline 0.1 & 1.5 & 0.319411 & 3.76107 \\
0.2 & 1.5 & 0.159705 & 1.88053 \\
0.3 & 1.5 & 0.106470 & 1.25369 \\
0.4 & 1.5 & 0.079853 & 0.94027 \\
0.5 & 1.5 & 0.063882 & 0.75221 \\
0.1 & 1.4 & 0.167274 & 3.12904 \\
0.1 & 1.3 & 0.060271 & 2.44791 \\
0.1 & 1.2 & 0.008630 & 1.70848 \\
0.1 & 1.1 & 0.000034 & 0.90188 \\
\hline
\end{tabular}

Titik-titik rancangan pada Tabel 1 memenuhi kriteria D-optimal seperti pada Persamaan (6). Sebagai ilustrasi ambil $\alpha=0.1$ dan $\beta=1.5$ dengan titik rancangan: $x_{1}=0.319411$ dan $x_{2}=3.76107$

Matriks informasi, invers matriks informasi dan fungsi dispersi (variansi terstandar) yang sesuai dengan rancangan $\xi$ pada Persamaan (8) adalah:

$$
\begin{aligned}
& \boldsymbol{M}(\xi)=\left(\begin{array}{cc}
0.24904 & -0.02202 \\
-0.02202 & 0.00299
\end{array}\right) \\
& \boldsymbol{M}^{-1}(\xi)=\left(\begin{array}{lc}
11.49850 & 84.61516 \\
84.61516 & 956.78452
\end{array}\right)
\end{aligned}
$$




$$
\begin{aligned}
\mathrm{d}(x, \xi) & =\boldsymbol{h}^{\boldsymbol{T}}(\boldsymbol{x}) \mathbf{M}^{-\mathbf{1}}(\boldsymbol{\xi}) \boldsymbol{h}(\boldsymbol{x}) \\
& =\left[\begin{array}{ll}
A_{1} & A_{2}
\end{array}\right]\left(\begin{array}{cc}
11.49850 & 84.61516 \\
84.61516 & 956.78452
\end{array}\right)\left[\begin{array}{l}
A_{1} \\
A_{2}
\end{array}\right]
\end{aligned}
$$

Variansi terstandar maksimum dari titik-titik rancangan diperoleh dengan memaksimumkan fungsi dispersi $\mathrm{d}(x, \xi)$ dengan metode modifikasi Newton. Titik maksimum dari $\mathrm{d}(x, \xi)$ di $(0.319411,2.0000000037)$ dan $(3.76107,2.0000000037)$. Secara grafis fungsi variansi terstandar seperti pada Gambar 2 berikut:

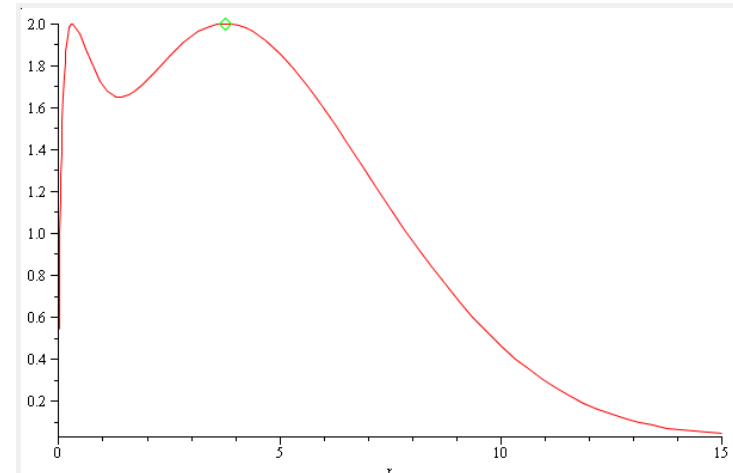

Gambar 2. Grafik d( $x, \xi)$ untuk Model (2) dengan $\alpha=0.1$ dan $\beta=1.5$

Berdasarkan Gambar 2, terlihat bahwa $\mathrm{d}(x, \xi) \leq 2$ sehingga rancangan $\xi$ seperti pada Persamaan (8) merupakan rancangan D-optimal untuk model eksponensial tergeneral seperti Persamaan (2). Hal ini karena berlaku Persamaan (8) yaitu: $\mathrm{d}(x, \xi)=\boldsymbol{h}^{T}(\boldsymbol{x}) \boldsymbol{M}^{-\mathbf{1}}(\xi) \boldsymbol{h}(\boldsymbol{x}) \leq \mathrm{k}=2$.

\section{Kesimpulan}

Dalam menentukan rancangan optimal peran peneliti sangat penting terutama pengetahuan ataupun berdasarkan percobaan yang telah dilakukan terdahulu tentang pola hubungan antara variabel faktor dan variabel respon yang akan dibangun. Pada model nonlinear diperlukan informasi awal tentang nilai parameter dalam model. Masalah rancangan D-optimal selanjutnya merupakan masalah optimasi yaitu memaksimumkan determinan matriks informasi. Rancangan D-optimal pada model eksponensial ini, berdasarkan fungsi determinan pada Persamaan (7), titik-titik rancangan merupakan titiktitik interior dari daerah rancangan.

\section{DAFTAR PUSTAKA}

1. Atkinson, A.C., Donev, A.N. and Tobias,R.D., Optimum Experimental Designs, with SAS, OXFORD University Press, 2007.

2. Antille, $\mathrm{G}$ et all., A Note On Optimal Designs In Weighted Polynomial Regression For The Classical Efficiency Functions. Journal of Statistical Planning and Inference, 2003, 113:285-292.

3. Dette, H., Melas, V.B. and Wong, W.K., Locally D-optimal Designs for Exponential Regression Models, Statistica Sinica, 2006: 16, 789-803.

4. Dette, H and Trampisch M., A General Approach To D-Optimal Designs For Weighted Univariate Polynomial Regression Models. Journal of The Korean Statistical Society, 2010, 39: 1-26.

5. Dette, H and Pepelyshev, A., Efficient Experimental Designs for Sigmoidal Growth Models. Journal of Statistical Planning and Inference, 2008, 138: 2-17. 
6. Fang, Z., D-optimal Designs for Weighted Polynomial Regression. Statistics \& Probability Letters, 2003, 63: 205-213.

7. Fang, Z., D-optimal designs for polynomial regression model through origin, Statistics \& Probability Letters, 2002, 57: 343-351.

8. Gang Li., Optimal and Eficient Designs for Gompertz Regression Models. Ann Inst Stat Math, DOI 10.1007/s10463-011-03040-y

9. Han,C. and Chaloner, K., D-and C-optimal Designs for Exponential Regression Models Used in Viral Dynamics and other Applications, Journal of Statistical Planning and Inference, 2003, 115: 585-601.

10. Imhof, L et all (2002), D-Optimal Exact Designs For Parameter Estimation In A Quadratic Model. Sankhya:The Indian Journal of Statistics, 2002, Vol 62, series B, Pt.2: 266-275.

11. Kiefer, J., and Wolfowitz, J., The Equivalence of Two Extremum Problems, Can. Jnl. Math, 1960, Vol. 12: 363-366.

12. Swhabe, R., Optimal Design for Linear and Nonlinear Models, A Short Course. Otto von Guerike University Magdeburg, July, 21-25, 2008.

13. Widiharih, T.,Haryatmi,S dan Gunardi, D-optimal Designs Untuk Regresi Polinomial Terboboti, IndoMS Journal on Statistics, 2013, Vol.1, No. 1. 